\title{
A Theoretical Model of Common Process Factors in Youth and Family Therapy
}

\author{
Marc S. Karver, ${ }^{1,3}$ Jessica B. Handelsman, ${ }^{1}$ Sherecce Fields, ${ }^{1}$ and Len Bickman ${ }^{2}$
}

\begin{abstract}
Recently there has been an increasing emphasis in the youth and family mental health treatment literature on the use of empirically supported treatments (ESTs). In contrast there has been scant attention paid to more universal aspects of the therapy process that may have even greater impact upon therapy outcomes. It is likely that the success of the techniques proposed by ESTs may depend on the presence of common process factors. In this article, the authors explore the status of common process factors research in the youth and family therapy literature, and propose a theoretical model linking specific therapeutic relationship variables and treatment outcomes for children and adolescents. This model is intended to guide synthesis of the empirical evidence for common process factors in youth and family treatment and to stimulate future research on common process factors.
\end{abstract}

KEY WORDS: theoretical model; common process factors; youth and family therapy; therapeutic relationship; therapeutic alliance; treatment outcome.

Over the past few decades, in response to increasing demands for more cost-effective and efficient treatment approaches, researchers associated with what has been called the empirically supported treatments (ESTs) movement set out to identify which therapeutic interventions work best for specific psychological problems (Sanderson, 2003). Division 12 of the American Psychological Association produced the most notable publications representative of this movement. On the basis of an exhaustive review of the adult treatment literature, the Division 12 Task Force on Promotion and Dissemination of Psychological Procedures produced lists of ESTs. A treatment approach was included only if the Task Force concluded that there was sufficient empirical evidence demonstrating its efficacy with a particular clinical population (Chambless, 1996;

\footnotetext{
${ }^{1}$ Department of Psychology, University of South Florida, Tampa, Florida.

${ }^{2}$ Vanderbilt University, Nashville, Tennessee.

${ }^{3}$ Correspondence should be directed to Marc S. Karver, $\mathrm{PhD}$, Department of Psychology, University of South Florida, 4202 East Fowler Ave; PCD 4118G, Tampa, Florida 33620; e-mail: mkarver@chuma1.cas.usf.edu.
}

Chambless \& Hollon, 1998). Lonigan, Elbert, and Johnson (1998) translated the division 12 criteria to the youth treatment literature. Other researchers in the child and adolescent treatment field have also produced reviews of ESTs (Burns, Hoagwood, \& Mrazek, 1999; Chorpita et al., 2002).

Although this shift towards evidence-based practice is likely to be beneficial for the mental health field, the EST movement has largely ignored more universal aspects of the therapeutic process that may be of even greater importance to treatment outcomes than the types of clinical interventions used. As Lambert and Barley (2002) noted, common process factors (i.e., relationship variables) reportedly account for $30 \%$ of the variance in adult treatment outcomes, above and beyond the $15 \%$ of variance accounted for by specific therapeutic techniques. Furthermore, empirical research suggests that one common factor, the therapeutic alliance, is among the most robust predictors of treatment outcomes for both adult and youth clients (Horvath \& Bedi, 2002; Shirk \& Karver, 2003). Recognizing the need for more research on common process factors, Division 29 of the American Psychological Association formed the Task Force on 
Empirically Supported Therapy Relationships to determine which relationship variables are evidencebased (Norcross, 2002). The Task Force concluded that demonstrably effective common process factors in adult treatment were goal consensus and collaboration, the therapeutic alliance, cohesion in group psychotherapy, and therapist empathy. In addition, several other relationship variables were identified to be promising and probably effective components of the therapeutic process in adult treatment.

The Task Force's omission of research from the child and adolescent field represents a major limitation of their work. It has been suggested that relationship variables may be equally, if not more, critical in youth and family therapy, as child and adolescent clients typically are not self-referred and often enter into treatment unaware of their problems, in conflict with their parents, and/or resistant to change (DiGiuseppe, Linscott, \& Jilton, 1996; Shirk \& Karver, 2003). It follows that developing a strong therapeutic relationship with young clients and/or their family members may reduce resistance to treatment and facilitate engagement by providing a stable, accepting and supportive context within which therapy may take place. Indeed, preliminary evidence suggests that common process factors are significantly related to clinical outcomes for children and adolescents. Most notably, Shirk and Karver (2003) reported that elements of the therapeutic relationship were moderately strong predictors of treatment outcome in their meta-analysis of the youth mental health services literature.

Common factors research first appeared in the child and adolescent literature in the 1970s (e.g., Truax, Altman, Wright, \& Mitchell, 1973), but few empirical studies were produced during the two decades that followed. Over the last several years, however, there has been a notable increase in the amount of research examining relationship variables in youth and family therapy. It is likely that enhanced interest in this area was triggered by increasing awareness that the use of ESTs is minimal in clinical practice (as many clinicians fear that manualized treatments will harm their relationship with their clients; Connor-Smith \& Weisz, 2003) and that mental health treatments have demonstrated limited effectiveness for children and adolescents in community settings (Weisz \& Jensen, 1999). Furthermore, the successful use of evidence-based practices is hindered by clients' poor session attendance, low treatment compliance, and premature termination (Weersing \& Weisz, 2002). In fact, research on mental health services delivered to youth in realworld settings has uncovered a treatment dropout rate ranging from 28 to $85 \%$ (Armbruster \& Kazdin, 1994; Garcia \& Weisz, 2002; Huey, 1998). As such, it is not surprising that some researchers have shifted their attention toward the identification of common process factors that may influence whether youth receive adequate exposure to the "active" components of treatment. ${ }^{4}$

Thus far, the common process factor research that has been done in the youth and family mental health treatment literature has not been systematic. Shirk and Karver's (2003) meta-analysis of this literature showed that almost every researcher was using a different measure of the therapeutic relationship. In addition, these studies did not appear to be driven by a cohesive theoretical model depicting the process by which elements of the therapeutic relationship contribute to clinical outcomes of youth. Surprisingly, such a model is also absent in the adult treatment literature.

In 1995, Arkowitz (1995) proposed that a future challenge for the field would be to develop models of the process by which common factors presumably affect therapeutic change. At present, most relationship constructs have been studied in isolation without any model or theory of how they are related to one another. Ideally, a model should guide how constructs are organized and tested. By designing studies that test the possible links between relationship variables and outcomes, researchers would be better able to understand how common process factors work. Thus, we present a model of how we believe therapeutic relationship constructs interact to affect outcome. We see this model as preliminary - a framework to be restructured and built-upon as more empirical evidence is gathered. Development of this therapeutic relationship construct model was guided by an attempt to follow the therapeutic process model criteria set forth by Sexton, Ridley, and Kleiner (2004): comprehensive, heuristic, metatheoretical, systematic, practical, simplistic without being overly simplistic, and clear.

\footnotetext{
${ }^{4} \mathrm{~A}$ recent search of the Computer Retrieval of Information on Scientific Projects (CRISP) database of federally funded research produced nine federally funded studies of the therapeutic alliance in youth treatment research. By comparison, a search of 5 years earlier only produced three such funded studies.
} 


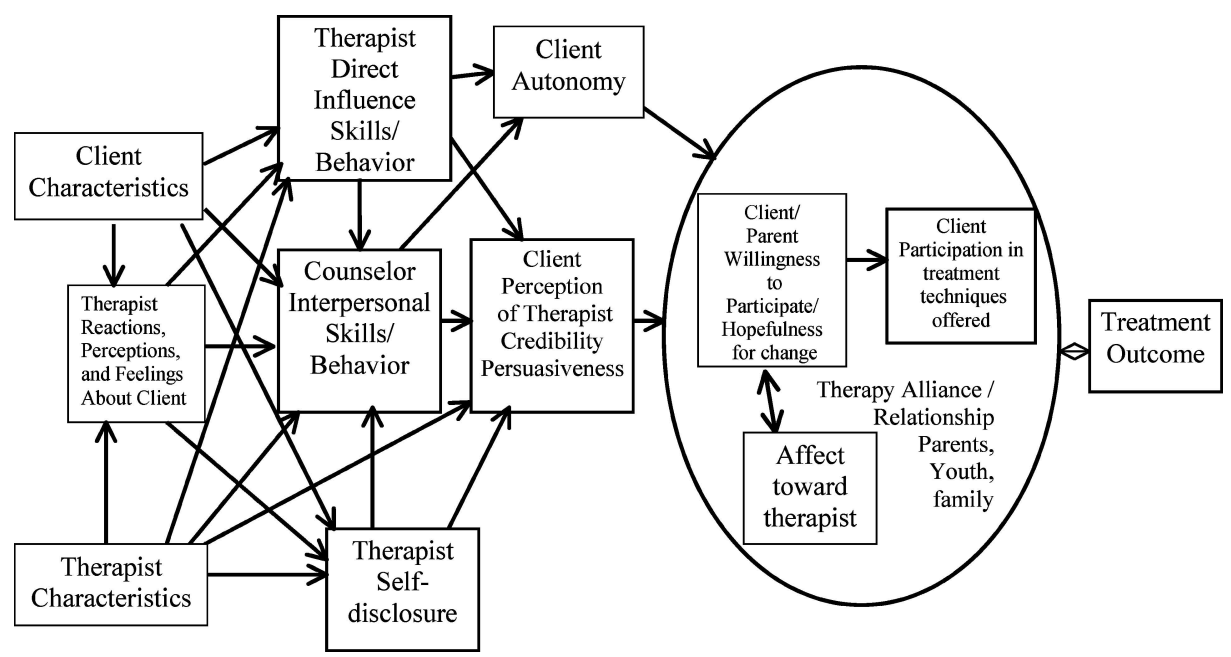

Fig. 1. Therapeutic relationship constructs treatment process model.

\section{THEORETICAL MODEL OF RELATIONSHIP VARIABLES AND TREATMENT OUTCOME}

Figure 1 displays the hypothesized model that links the various relationship variables and treatment outcome. Consistent with most mental health research, we conceptualize treatment outcome as decreasing the severity of mental health symptoms, improving level of functioning, developing coping abilities and strengths, and decreasing level of distress experienced by the youth and/or family members (Salzer, Nixon, Schut, Karver, \& Bickman, 1997). In general, the model suggests that therapeutic relationship variables may affect therapeutic outcomes through several mediating processes. First, a client (parent, child, family members) enters treatment with several pretreatment characteristics that affect how receptive the client is to the therapist and therapy. Next, therapist characteristics and client characteristics influence the therapist's perceptions of and feelings/expectations about their client(s). These reactions affect the therapist's behavior towards the client, which in turn influences the client cognitively, affectively, and behaviorally. This occurs early in treatment but also continues as an ongoing dynamic process. These proximal changes are how the youth and/or family members utilize the specific techniques of any treatment approaches (such as the ESTs) such that these approaches lead to positive treatment outcomes. In the following section, we review some of the conceptual basis for linking the components of the model in the manner that we have presented. It is our hope that this conceptual framework will guide further research on common process factors in youth therapy.

\section{CLIENT PRETREATMENT CHARACTERISTICS}

By client pretreatment characteristics, we refer to individual characteristics that clients (youth, parents, and family members) bring with them to their first therapy session. These characteristics include youth presenting problems, youth age/developmental status, youth, parent, and/or family member interpersonal functioning, parental mental health, parental intelligence, family environment, child and parent expectancies of mental health efficacy and treatment acceptability, etc. (Fields, Handelsman, Karver, \& Bickman, 2004). As one might suspect, the characteristics that youth and their parents bring to treatment have a prominent impact on how therapy proceeds and on the ultimate outcomes of treatment (Clarkin \& Levy, 2004). In fact, Lambert (1992) stated that $40 \%$ of the variance in therapy outcomes is accounted for by pretreatment characteristics.

Relative to our model, we propose that therapist behaviors are contingent upon the pretreatment characteristics that clients (youth, parents, family members) bring to therapy. For example, Karver, Lambert, and Bickman (2003) found that therapists were most likely to point out strengths (a counselor 
interpersonal skill) in those youths who entered therapy with the most pretreatment strengths. Hardy, Stiles, Barkham, and Startup (1998) found that therapists used different interpersonal ways of relating and different levels of directive behavior depending on the pretreatment interpersonal/attachment levels of their clients. In an early study, Haccoun and Lavigueur (1979) found that therapists used different levels of supportive and directive interventions depending on the characteristics of psuedoclients. Keithly, Samples, and Strupp (1980) concluded that clients' initial level of motivation impacted the behavior of therapists. Bohart, Elliot, Greenberg, and Watson's review (2002) notes several studies that found client level of psychopathology, intelligence, self-esteem, and motivation to impact the level of empathy expressed by therapists. Hill and Knox (2002) suggest that therapist self-disclosure should depend on client characteristics but there is no research that documents what these characteristics should be. Not surprisingly, when therapist behavior has not been responsive to pretreatment client characteristics (e.g., being directive with a resistant client), this has often resulted in poor treatment outcomes (Beutler, Rocco, Moleiro, \& Talebi, 2001). However, as important as this probably is, a literature search revealed that very little work has examined the impact of client characteristics on therapist behavior in youth mental health treatment research. In fact, the clinical literature emphasizes the importance of therapists varying their behavior based on the developmental characteristics that youth clients bring to treatment, however, there has been extremely little research done that has examined children's social, emotional, peer, biological, and cognitive development and how these characteristics affect therapist behavior toward the child client and their parents (Kendall \& Choudhury, 2003; Shirk, 1999; Weisz \& Hawley, 2002). Furthermore, there have been several studies that have measured parental characteristics such as parental mental health (e.g., Hutchings, Appleton, Smith, Lane, \& Nash, 2002; Luk, Staiger, Mathai, Field, \& Adler, 1998), but there are no studies that examine therapist responses to these parental characteristics. This is a very important area to explore considering that parental characteristics such as parental psychopathology and stress have been found related to poor parenttherapist relationship, poor parental treatment participation, and poor treatment outcomes (Kazdin \& Wassell, 2000). Thus, additional research is needed to examine the hypothesized link between client(s) pretreatment characteristics and therapist behaviors such as therapist self-disclosure, counselor interpersonal skills/behaviors, and therapist direct influence skills/behaviors.

\section{THERAPIST PRETREATMENT CHARACTERISTICS}

In addition to client characteristics influencing therapist behaviors, one would expect that therapist characteristics such as theoretical orientation, personal distress, interpersonal skills, or personality characteristics should also influence therapists' insession behaviors (Llewelyn \& Hardy, 2001). Bohart et al.'s review (2002) found several therapist characteristics, such as cognitive complexity and openness to conflictual feelings, were related to in session empathy in adult outpatient treatment. However, as with client characteristics, there has been minimal study of therapist characteristics predicting therapist behavior. Considering the prominent role of therapists in delivering therapy to their clients, this is quite amazing. In 1997, Garfield noted that the therapist was a neglected variable in psychotherapy research. This appears to still be true (Ackerman \& Hilsenroth, 2003; Carroll, 2001; Weinberger, 2002). In the mental health literature in general, and specifically in the youth treatment literature, research is needed to see if certain types of therapists are more likely to self-disclose, if certain therapists are more likely to have interpersonal skills and behaviors, and if certain types of therapists are more likely to use direct influence skills/behaviors.

\section{THERAPIST REACTIONS, PERCEPTIONS, AND FEELINGS}

Figure 1 shows that we expect that therapist reactions, perceptions, and feelings/expectations about their clients may be an important mediating link between therapist and client pretreatment characteristics and therapist behaviors. The idea behind this link in the model comes from consideration of the extensive literature on social information processing (e.g. Crick \& Dodge, 1994; Milner, 2003). Therapist characteristics likely influence the perception of client characteristics, called social situational cues. When therapists perceive these client cues, they then likely engage in mental steps that generate social cognitions such as attributions about why clients are engaging 
in certain behaviors, considerations of various options on how to engage the client, and evaluations of their likely efficacy in influencing the behavior of the client. These social cognitions than lead to therapist affective reactions which may influence their actual choice of and implementation of therapist behaviors.

There appear to be a number of studies that support this social information processing conceptualization. Client characteristics such as gender, attachment state, self-image, and aggressive and suicidal behavior have been found to lead to therapist reactions such as positive and negative feelings about the client and therapist perceptions of the likelihood of a client engaging in treatment (e.g. Armelius \& Holmqvist, 2003; Bernier \& Dozier, 2002; Holmqvist, 1998; Kiesler, 1996; Rossberg \& Friis, 2003). Therapist source characteristics such as therapist gender, self-image, experience, unresolved therapist conflicts have also been found related to therapist reactions toward clients such as having distracting thoughts, positive and negative feelings about clients (called counter-transference in a large number of studies), and feelings of confusion, anxiety, and boredom (Armelius \& Holmqvist, 2003; Rosenberger \& Hayes, 2002; Williams, Polster, Grizzard, Rockenbatjgh, \& Judge, 2003). However, this literature has been plagued by having mostly analogue studies with very few studies of real world mental health services. In addition, the area of counselor reactions to clients appears to be grossly neglected in the youth mental health literature with several vignette studies finding youth presenting problems, psychological distress of the therapist, and therapeutic orientation of the therapist related to therapist feelings (countertransference) toward clients (Dube \& Normandin, 1999; Shachner, 1995) and a small case study of countertransference resulting from child and parent characteristics (Gabel \& Bemporad, 1994).

A number of studies in the adult treatment literature also exist supporting the link between therapist perceptions of clients and subsequent therapist behavior. Therapist's accurate perceptions of client reactions and counselor's perceived ability to succeed in counseling a client, counseling self-efficacy, have been found related to higher ratings of therapist in session behaviors (Larson et al., 1992; Thompson \& Hill, 1991; Wester, Vogel, \& Archer, 2004). Ackerman \& Hilsenroth's (2003) review suggests that therapist's emotional reactions to clients undermine their ability to attend to clients and convey warmth, trustworthiness, concern, engagement, and other interpersonal characteristics. Williams, Judge, Hill, and Hoffman (1997) found that trainees who had difficulty managing their internal reactions often engaged in negative or incongruent behaviors such as displaying annoyance or becoming overly directive. The type of cognitions a therapist has with a client can also be very important relative to the therapist behavior that follows. For example, Williams (2003) found that therapists who had frequent cognitions about their own actions relative to their client were more likely to engage in less helpful behavior with their client. In addition, distracted novice therapists have been found to be the most likely to use self-disclosure (Williams et al., 2003). A number of studies have found therapist expectancies of treatment outcomes related to treatment outcomes but unfortunately nothing is known about whether or not therapist behaviors mediated this relationship (Joyce, Ogrodniczuk, Piper, \& McCallum, 2003; Meyer et al., 2002). There do not appear to be studies in the youth mental health literature examining this link in our conceptual model. Considering the findings in the adult literature, this is an area needing research in the youth treatment literature.

\section{COUNSELOR INTERPERSONAL SKILLS}

Counselor interpersonal skills represent several relationship constructs that have been labeled as counselor provided facilitative conditions; therapeutic combined conditions of empathy, warmth, and genuineness; importance of the therapeutic relationship; counselor source characteristics; trust, empathy, warmth and positive regard. It has been suggested that these variables promote clients' growth, self-actualization, and self-direction in treatment (Cormier \& Nurius, 2003). Thus, in our model, we propose to link these skills with the construct client autonomy.

Research in this area first appeared in the youth treatment literature in the $60 \mathrm{~s}$ with a school-based study of youth with behavioral problems by Hansen, Zimpfer, and Easterling (1967) and in the early 70 s with research by Truax with institutionalized juvenile delinquents (1971). However, research on counselor interpersonal skills originated in the adult treatment literature, with the early writings of Carl Rogers (1951). Truax (1961) was one of the first researchers to operationalize and study these skills when he generated scales of empathic understanding, accurate empathy, unconditional positive regard, and 
self-congruence. Rogers (1951) proposed that the helper must effectively use these skills in order for the client to perceive an optimal therapeutic environment. In this optimal therapeutic environment, the therapist conveys warmth, respect, and positive regard. Effective use of these interpersonal skills requires that the therapist demonstrate caring and concern for the client, interest in what the client talks about, acceptance of what the client talks about, and encouragement of the client's efforts. In this optimal environment, the therapist is seen as trustworthy; dependable, honest, and genuine. The therapist is also seen as empathic; the therapist is able to understand and relate to the client's experience and frame of reference and express this sense of understanding. It is believed that in receiving empathic responses, clients feel respected and validated and believe their thoughts and feelings have value. This would result, as indicated in our model, in positive affect toward the therapist and the development of a strong therapeutic alliance. Ackerman and Hilsenroth's (2003) review presents evidence of the relationship between counselor interpersonal skills and the therapeutic alliance in that they found that counselor's lack of empathy, disrespect, and lack of acceptance of clients led to poor therapeutic alliances. Farber and Lane (2002) suggest that the counselor interpersonal skill of positive regard may operate by facilitating a longterm working relationship. Counselor interpersonal skills are also believed to encourage clients to explore and reprocess their ways of thinking and feeling in session with the therapist, that is, to participate in treatment (Truax \& Carkhuff, 1965). This optimal therapeutic environment is believed to be necessary (but not sufficient) to achieve positive treatment outcomes.

Strong's interpersonal influence model (1968) offers an alternative view of these counselor interpersonal skills. Accordingly, therapist interpersonal skills serve to socially influence the client. The client is influenced or persuaded to do what the therapist suggests because the therapist has established him or herself through his/her characteristics and behaviors as credible. These interpersonal skills allow therapists to induce their clients to reveal information and change their attitudes. Bohart et al. (2002) propose that empathy, and we suggest maybe counselor interpersonal skills in general, could lead to positive outcomes through the client feeling understood, having a sense of satisfaction with the therapist and thus wanting to comply with treatment recommendations, through being a corrective emotional experi- ence, through promoting exploration and productive thinking, or through promoting client's self-healing active involvement. Research on these proposed links is limited in the adult literature and complicated by the fact that client ratings (perceptions of the occurrence) of these therapist behaviors are more predictive than observer ratings of these behaviors (Bohart et al., 2002). The research is even more limited in the youth mental health treatment literature.

\section{THERAPIST SELF-DISCLOSURE}

Therapist self-disclosure has been examined in only one youth mental health treatment process to outcome study with outpatient youth clients described as having self-control problems (Braswell, Kendall, Braith, Carey, \& Vye, 1985). This is surprising considering that the construct was first examined in an analogue study with child clients in 1969 (Myrick, 1969). Self-disclosure can be defined as whether individuals provide information about themselves (their thoughts and feelings) or their personal activities and experiences (Hill \& Knox, 2002). Information can be provided spontaneously or in response to questioning.

Therapist self-disclosure is a controversial area. Many clinicians, researchers, and theorists believe that it facilitates the formation of a therapeutic alliance with a client by providing a warm, understanding, and empathic connection with the therapist where as others believe that it distracts from a focus on the client's issues and is not a connecting counselor interpersonal skill (Barrett \& Berman, 2001). So, as shown in our model, it could facilitate the therapeutic relationship and lead to client's participation in treatment (such as with client disclosure). Barrett and Berman discuss how prior research has shown that it could impact ratings of counselor interpersonal skills as disclosing counselors may be perceived as having friendly, open, and warm behaviors. Alternatively, self-disclosure may have a negative impact on a client's perceptions of the therapist's credibility if drawing attention to the therapist's own vulnerabilities undermines the client's perception of the therapist as an authority. Lastly, their article suggests that the effects of therapist self-disclosure could depend on what is disclosed and when it is disclosed (relative to client statements). Considerably more research is needed on this issue in the youth mental health treatment literature. 


\section{THERAPIST DIRECT INFLUENCE SKILLS}

Therapist direct influence skills are measures of directive therapist behavior. They include constructs that have been labeled as therapist clarity, therapist ability to provide an understandable rationale, therapist provision of feedback, therapist direct guidance, therapist active structuring, and therapist directive support. Examples would include the therapist giving clear instructions or making clear communications with the client, the therapist clearly explaining the rationale for treatment, the therapist organizing the content of therapeutic sessions, the therapist offering corrective feedback or reinforcement for correct behavior, and the therapist offering advice or modeling expected behavior (Bennum, 1989; Braswell et al., 1985; Gorin, 1993; Green, 1996; Green \& Herget, 1991; Sapyta, Karver, \& Bickman, 1999). The benefits of therapist direct influence methods appear to be controversial. These various ratings of therapist verbal behavior are suggested to either lead directly or indirectly to the therapist being able to influence/persuade a client to change attitudes or behaviors (Hoyt, 1996). If the therapist presents him/herself clearly, confidently, and directly, he/she can be perceived as credible in using therapeutic techniques (Ackerman \& Hilsenroth, 2003). In addition, therapist direct influence behaviors may serve as a form of role induction meant to establish the credibility of the therapist and the therapy that will be delivered (Frank, Frank, \& Cousins 1993). However, many clinicians believe that these therapist behaviors detract from client self-direction (or autonomy) and may lead to client resistance (lack of treatment participation) or dependency on the therapist. It also has been suggested that if a therapist uses too many of these directive behaviors, that this will negatively affect ratings of the counselors interpersonal skills (warmth, empathy, etc.), however, this has not typically been found in the adult treatment literature (Keijsers, Schaap, \& Hoogduin, 2000). In addition, McKay, Stoewe, McCadam, and Gonzales (1998) found that therapist active engagement strategies with families, such as explaining the helping process, actively focusing conversation onto immediate and practical concerns, and directly addressing barriers to treatment, resulted in greater family retention into treatment. Coatsworth, Santisteban, McBride, and Szapocznik (2001) have also found evidence that directive Brief Strategic Family Therapy strategies, such as restructuring family interactions, assigning behavioral tasks, taking a leadership role in therapy, and providing a rationale for treatment, contribute to family members' engagement and retention in treatment. Unfortunately, neither line of research has isolated specific therapist behaviors to examine their relationship to other treatment processes or treatment outcomes. Braswell et al. (1985) conducted the first child/adolescent process to outcome study examining a specific therapist direct influence skill. Interestingly, these variables have been studied several decades previously in the children's mental health literature without looking at impact on outcomes (e.g., Hartley, 1969).

\section{THERAPIST CREDIBILITYI PERSUASIVENESS}

Figure 1 shows that we expect that therapist credibility and persuasiveness will be an important mediating link between therapist behaviors and various aspects of the therapeutic relationship. The idea behind this link in the model is that therapist behaviors and characteristics, called credibility cues, cause the client to perceive the therapist as credible. Strong (1968) defines a credible person or therapist as one who is perceived to be attractive, to be trustworthy, and to have expertise. This perception of credibility of the therapist then convinces the client that it is worthwhile to form a working relationship or alliance with the therapist. In other words, the therapist then influences the client. Influence has been defined as client attitude change and/or behavioral compliance with the therapist (Hoyt, 1996). These links in the model follow from Strong's (1968) model of social influence in counseling. Hoyt's (1996) meta-analysis of the adult treatment literature on therapist credibility confirms that credibility cues are moderately related to credibility and that credibility is strongly related to therapist influence and therapeutic outcomes. Also from this meta-analysis, Hoyt (1996) suggested that credibility likely influences clients' attitudes about therapist helpfulness and satisfaction with the therapeutic relationship prior to influencing observable client behavior. In other words, credibility influences cognitive and emotional aspects of therapy attitudes by instilling positive expectations, hope, and faith about attempting to change one's behavior (Frank et al., 1993). The client is convinced to be realistically hopeful about change and to remain in treatment long enough to be persuaded to utilize the therapist's techniques to change his/her ways of feeling, thinking, and/or behaving. 
As has been typical of most of the mental health treatment literature, the credibility literature is overwhelmingly on the basis studies with adult clients (there are a few studies with adult samples that included some adolescent clients as young as age 16). This adult treatment literature has found therapist credibility and influence to be related to degree of patients' treatment engagement and compliance, relationship with the therapist, and number of sessions attended (e.g., Kalman, 1983; Kirsch \& Henry, 1977; Nelson \& Borkovec, 1989; Scheel, Seaman, Roach, Mullin, \& Blackwell-Mahoney, 1999).

We were able to find four analogue adolescent treatment credibility studies that were from the 1980's (Atkinson \& Schwartz, 1984; Bernstein \& Figioli, 1983; Lee, Hallberg, Jones, \& Haase, 1980; Littrell, Caffrey, \& Hopper, 1987) and one actual treatment credibility study (Stein et al., 2001). Obviously, more research is needed in the youth mental health treatment literature to see if this is also an important common process factor in youth-therapist interactions.

\section{AUTONOMY}

Autonomy has been studied as a therapeutic relationship construct in only one youth treatment study conducted almost 20 years ago in a school-based setting (Taylor, Adelman, \& KaserBoyd, 1986). The researchers theorized that a client's demonstration of self-direction in his/her relationship with the therapist would be an important therapeutic process. In fact, they felt that, without a sense of autonomy, a client would be dependent on the therapist, which would undermine any motivation to work in therapy. Thus, an autonomous client would feel that he or she could decide what to do during treatment and could feel free to bring up current problems without having to wait for therapist permission. In the substance abuse treatment literature, evidence has been provided for a relationship between client sense of autonomy and motivation to change (Simoneau \& Bergeron, 2003). Thus, in our model, we suggest that client autonomy may result from several therapist behaviors that encourage the client's independence during the therapy process. It is hypothesized that these behaviors would be less directive and more likely to be supportive and encouraging. If the client does develop this sense of autonomy in the therapeutic process, the client may be more likely to form a therapeutic relationship with the therapist and be willing to participate in treatment techniques offered by the therapist. Considering the lack of research on autonomy in the therapeutic process with youths, all aspects of this construct and its relationship with other constructs would require further study.

\section{AFFECT TOWARD THE THERAPIST}

Affect can be defined as the conscious, subjective aspect of feeling or emotion (Merriam-Webster's Collegiate Dictionary, 2003). Affect toward the therapist has been studied in only one youth mental health treatment process to outcome study-a dissertation conducted at a residential treatment center with abused and neglected youth by Berg (1999). Finding only a single study is surprising considering that the construct was first examined almost 20 years earlier with children (Howe \& Silvern, 1981). However, research focusing explicitly on this construct may be limited because it became viewed as a fundamental part of the therapeutic alliance constructthe emotional, affective bond between the client and the therapist (DeVet, Kim, Charlot-Swilley, \& Ireys, 2003)-rather than an independent construct. Research in the adult literature suggests that this affective bond is a separate component from other aspects of the therapeutic alliance (Hatcher \& Barends, 1996). It is hypothesized that this emotional connection between the therapist and the client is a precursor to the youth client being willing to work with the therapist. If the client has positive feelings toward the therapist and feels that the therapist cares about him/her, then the client may be more likely to be willing to consider the suggestions or try the techniques offered by the therapist. Then the client will be more likely to participate in treatment, which would lead to positive outcomes. There is some research that suggests that the link between bond and willingness to participate may be a necessary step for treatment success as opposed to just having an emotional connection with the therapist (Weerasekera, Linder, Greenberg, \& Watson, 2001). However, this link may depend on the type of therapy that is being delivered. Weerasekeera et al. (2001) suggest that the bond component may be more directly related to treatment outcome in psychodynamic and humanistic treatments that are more focused on changes in interpersonal relationships 
and self-esteem. Interestingly, outside of the therapy literature, there is some support for the hypothesis that the affective relationship with the therapist leads to a willingness to participate and hopefulness about change, and that this leads to actual participation in treatment. Bandura, Caprara, Barbaranelli, Gerbino, and Pastorelli (2003) discuss how positive affect enhances perceived self-efficacy (a belief in one's ability to perform in various domains) and how this leads to stronger engagement in activities. Accordingly, negative affect would lead to less belief in one's abilities and less engagement in activities. Erez and Isen (2002) found that the experience of positive affect led to participants having higher levels of expectancy regarding the link between effort and successful performance. In addition, the rewards of performance are perceived to be even more likeable. Perhaps the same process occurs in therapy, with the experience of positive affect toward the therapist leading to positive expectancies about the benefit of participating in treatment and higher levels of actual involvement. On the other hand, cognitive theorists could envision a process whereby therapist behaviors are experienced as events, the client has thoughts and beliefs about these events (beliefs of whether or not what the therapist suggests may be helpful, etc.), and this leads to the client having an emotional reaction toward the therapist (Padesky \& Beck, 2003). Research looking at the relationship between the separate components of the therapeutic alliance in the youth mental health treatment literature is sorely lacking and needed.

\section{WILLINGNESS TO PARTICIPATE IN TREATMENT}

Willingness to participate in treatment also has been examined in only one youth process-outcome treatment study (several constructs were used which all seemed to be addressing willingness to participate). Willingness to participate includes constructs that have been labeled as client-rated desire for therapy, client-rated perceived importance of therapy, client-rated perceived time spent on important matters, and client rated commitment (Adelman, Kaser-Boyd, \& Taylor, 1984). This domain appears to overlap with the cognitive connection component of the therapeutic alliance and has often been included as part of therapeutic alliance measures. Across various definitions, it appears to be examining the client's readiness to change through treatment, the client's perception that the therapy offered is relevant and not too difficult to assist change, and the client's self-efficacy/hopefulness beliefs about change (the client believes he/she has the ability to change through treatment) (Bohart, 2000). We hypothesize that it is likely that the degree to which the client likes the therapist could impact the client's willingness to participate in treatment. Furthermore, it seems reasonable to expect that clients who are willing to participate in treatment would be most likely to adhere to (participate in) treatment and be less likely to drop out of treatment. This construct was first examined in the youth mental health treatment literature in the 80 's in a school-based study (e.g., Adelman et al., 1984) but then was not investigated for over a decade. Again, it may be that the construct has been subsumed within general therapeutic alliance measures. However, interest in parents' willingness to participate has surfaced recently with the work of Kazdin with parents of youth with disruptive behavior disorders (Kazdin, 2000).

\section{PARENTAL WILLINGNESS TO PARTICIPATE IN TREATMENT}

Parental willingness to participate in treatment has been studied in two child and adolescent mental health treatment process to outcome studies. Parental willingness to participate includes constructs that have been labeled as perceptions of barriers to treatment participation and treatment acceptability. It appears to overlap with the cognitive connection component of the parental therapeutic relationship. It is quite similar to child/adolescent willingness to participate in treatment; however, the adult definition has more emphasis on factors that may influence the decision to participate in treatment. It appears to be examining the parents' perception that the therapy offered is relevant and not too difficult to participate in. It seems reasonable to expect that parents who see the therapist as credible and supportive would be more willing to overcome obstacles and participate in treatment and thus would be most likely to adhere to (participate in) treatment and be less likely to drop out of treatment. This construct was first examined in parents in the child mental health treatment literature in 1977 (Kazdin, 1977). Considerably more research is needed in this 
area as parents most likely play an important role in the delivery of treatment to youths and may impact youth responsiveness to treatment (Fields et al., 2004).

\section{CLIENT PARTICIPATION IN TREATMENT}

Adelman et al. (1984) were the first to explore empirically client participation in the child mental health treatment literature. However, it was studied even earlier in the adult treatment literature (Bellak \& Smith, 1956; Kirtner \& Carwright, 1958; Strupp, Chassan, \& Ewing, 1966). Client participation includes constructs that have been labeled as client effort, collaboration, client involvement in therapy, cooperation, treatment engagement, on-task behavior, and homework completion (Adelman et al., 1984; Braswell et al., 1985; Clarke et al., 1992; Gorin, 1993; Green, 1996; Johnson, 2000; Sarlin, 1992; Tolan, Hanish, McKay, \& Dickey, 2002). These studies have explored client participation with a wide variety of clients across numerous treatment settings such as school-based clinics, outpatient mental health clinics, and home-based treatment. Client participation appears to overlap with the positive treatment behaviors component of the therapeutic alliance and has often been included in therapeutic alliance measures. According to several definitions participation occurs when the client proceeds mentally or physically with the steps/tasks of therapy. A participating client would be seen as cooperating with, being involved in, making suggestions about, and/or completing therapeutic tasks. A participating client would also be one who completed therapeutic homework and in-session assignments. This can include (if appropriate to the tasks of therapy): verbally discussing feelings and experiences in session and responding to therapist requests (Jackson-Gilfort, Liddle, Tejada, \& Dakof, 2001; Tolan et al., 2002). In addition, Colson et al. (1991) defined hostility, inaccessibility, and treatment difficulty as lack of client participation in a study of hospitalized adolescents. This construct seems to be a critical part of a successful treatment process. If a client likes his/her therapist but does not participate in treatment or resists treatment, then it is unlikely that the client will be able to utilize the therapist to achieve therapeutic change. In fact, Smith and Grawe (2003) conclude that it is the quality of the patient's collaboration that is most strongly associated with session and therapy outcomes. As one might imagine, it is expected that parental participation in treatment may also play a critical role in successful youth mental health treatment.

\section{PARENTAL PARTICIPATION IN TREATMENT}

This parental construct was first explored empirically in the child mental health treatment literature by Chamberlain, Patterson, Reid, Kavanagh, and Forgatch (1984). It has been defined minimally as the attendance of one or both parents at therapy sessions. We do not consider this to be an adequate measure of parental participation, as merely being present for sessions does not inform us about the degree of participation and engagement in treatment. Parent participation includes constructs that have been labeled as parent involvement and parental treatment investment (e.g., Nye, Zucker, \& Fitzgerald, 1999). It appears to overlap with the positive treatment behaviors component of the parental therapeutic relationship. Across various definitions, it appears to be examining the parent's proceeding mentally or physically with the steps/tasks of therapy. A participating parent would be seen as cooperating with, being involved in, making suggestions about, and/or completing therapeutic tasks. A participating parent would also be one who completed therapeutic homework and in-session assignments. This can include, if appropriate to the tasks of therapy: verbally discussing feelings and experiences in session and responding to therapist requests. Some researchers also see parent involvement problems, guardedness, avoidance, devaluing of treatment procedures, and treatment resistance as the negative version of parental participation (Chamberlain et al., 1984; Colson et al., 1991; Stoolmiller, Duncan, Bank, \& Patterson, 1993). This construct may also be related to more recent work on parent empowerment (Bickman, Heflinger, Northrup, Sonnichsen, \& Schilling, 1998).

This construct also may be critical to the success of treatment. If a parent likes the therapist but does not participate in treatment, then it is unlikely that the parent will be able to utilize the therapist to achieve therapeutic change. In addition, without parental involvement, it may be less likely that therapeutic changes implemented with a child client will be generalized to the home setting. 


\section{THERAPEUTIC RELATIONSHIP WITH THE YOUTH CLIENT}

The therapeutic relationship with the child (as a construct unto itself) has been studied in five processto-outcome studies, starting in 1988 with a dissertation conducted at a residential treatment center by Fogle. Shirk and Saiz (1992) noted that the therapeutic relationship with the child has been considered a prerequisite for any work in child therapy dating to the work of Sigmund and Anna Freud in the 1940s (Freud, 1946). When examining empirically supported treatment relationships, Norcross (2002) used Gelso and Carter's (1985) definition of the therapeutic relationship: "the feelings and attitudes that therapist and client have toward one another, and the manner in which these are expressed" (p. 7) Unlike the adult literature, where the therapeutic relationship has been considered a category of variables, the child treatment literature has frequently used this general term as a variable itself defined in numerous but similar ways. Most typically, the therapeutic relationship has been defined in a manner that is parallel to definitions of the therapeutic alliance (see later section). Not surprisingly, being a general term, it has also included elements not typically associated with the therapeutic alliance. Most commonly it has been defined as an emotional connection that has been labeled as affective attachment, affective bond, affective experience of the client, client's perception of therapist's affect, social support, trust, and comfort. Sometimes it has been additionally defined as a cognitive connection (e.g., agreement on goals). It has also referred to the client's behavior toward the therapist, including collaboration on therapeutic tasks, negativity toward the therapist, openness in talking during sessions, and involvement in developing a treatment plan. Additional definitions have been included that have not been used for traditional therapeutic alliance definitions such as having commonality of interests with the clinician. Research is severely lacking in the youth mental health treatment literature on the links between these various aspects of the therapeutic relationship and how it is affected by therapist behaviors.

\section{THERAPEUTIC ALLIANCE WITH THE YOUTH CLIENT}

According to Shirk and Saiz (1992), the therapeutic alliance is a more mature form of the ther- apeutic relationship. The therapeutic alliance has been studied as a therapeutic relationship construct in the child literature in 10 process-to-outcome studies, the first of which was conducted over a decade ago (Colson et al., 1991). This domain has been explored much more extensively and earlier in the adult mental health treatment literature, with the first adult therapeutic alliance to outcome study dating back to Gomes-Schwartz (1978). As in the adult literature (Horvath \& Bedi, 2002), the therapeutic alliance with children has been defined several different ways. Most commonly the alliance has been defined as some type of relational connection with a therapist: exclusively an emotional connection or exclusively a cognitive connection or a combination of both of these elements. This emotional connection has been referred to as bond, trust, acceptance, warmth, mutual positive regard, feeling allied, supportiveness, and helpfulness. The cognitive connection has been called agreement on goals or tasks, and positive working relationship. Others have also included in their definitions of the therapeutic alliance the behavior of the client toward the therapist. This includes treatment defeating or undermining behavior of the client such as distorting information, being hostile toward the therapist, negativity, and not complying with the therapist or positive treatment behaviors by the client such as actual participation or collaboration in therapeutic activities such as confiding in the therapist or attempting therapeutic skills. It is believed that the therapeutic alliance might influence outcomes of treatment in several different ways: either as a necessary relational change mechanism, as a catalyst for other treatment processes that lead to positive outcomes, or as a moderator of therapist offered interventions (Shirk \& Karver, in press; Bickman et al., 2004). As with some of the other youth relationship constructs, the parental version of this construct may play an important role in treatment.

\section{THERAPEUTIC RELATIONSHIP WITH THE PARENT(S)}

The therapeutic relationship with parents has been studied as a therapeutic relationship construct in nine treatment process to outcome studies starting back in 1991 with a study by Colson et al. (1991). In the literature that examines the parent therapeutic relationship and outcomes, the therapeutic relationship has been defined in ways that 
are similar to therapist-child and therapist-adult alliance/relationship definitions. These definitions also include an element of emotional connection referred to as the emotional bond or therapeutic helpfulness. Several definitions have also included the cognitive connection component of agreement on goals and agreement on tasks, and have also included positive working relationship and parent willingness to participate in treatment, parent perception that treatment is clear, makes sense, and is appropriate. Once again, some researchers have also had as part of the parent-therapist relationship the behavior of the parent toward the therapist. This includes treatment defeating or undermining behavior such as being hostile toward the therapist or positive treatment behaviors such as actual participation, collaboration, or engagement in therapeutic activities.

It is believed that the therapeutic relationship with the parent might impact outcomes of treatment in several ways: the treatment may be focused on directly changing parent behavior that will impact child behavior and thus engaging the parent will be critical, or, if the treatment is focused on the child, engaging the parent will be important because parents schedule and keep appointments, provide information about the child to the therapist, encourage the child's treatment adherence, and promote generalization of treatment gains outside of therapy sessions (Fields et al., 2004). In some circumstances, the treatment may include even more members of the family and thus the therapeutic alliance with the family must be considered.

\section{THERAPEUTIC ALLIANCE WITH THE FAMILY}

The therapeutic alliance with families has been studied as a therapeutic relationship construct in only four treatment process-to-outcome studies. Concerned that the mental health field had been overly focused on individual therapeutic alliances, Catherall (1984) was the first researcher to propose a family therapeutic alliance measure. In the limited literature that examines the relationship between family therapeutic alliance and treatment outcomes, the alliance has consistently been defined based on Bordin's (1979) three-part model (bond, collaboration on tasks, and agreement on goals. This model was expanded by Pinsof (1995) in that Bond, tasks, and goals were seen as the content domains of the family therapeutic alliance. In addition, an interper- sonal dimension was added to capture the variety of alliances that can exist in family therapy. Johnson and Wright (2002) have criticized this conceptualization of the alliance for not taking into account the unique relationship processes that exist in family therapy. At this time, no alternate family alliance model has been suggested or studied and additional research is obviously needed to examine how this construct relates to other relationship variables and treatment outcome.

\section{DISCUSSION}

In the youth mental health treatment field, one would be hard-pressed to find clinicians or researchers who do not believe that therapeutic relationship variables are important. Surveys have shown that clinicians who provide mental health services to child and adolescent clients highly value the therapeutic relationship (Bickman et al., 2000). The metaanalysis by Shirk and Karver (2003) also showed that therapeutic relationship variables are predictive of youth treatment outcomes. Yet, little is known about how these therapeutic relationship variables contribute to positive treatment outcomes. There is a need for a theoretical model that proposes a testable theory of how these constructs contribute to treatment outcomes. However, a theoretical model depicting the relationships between the various common process factors and treatment outcomes has not been proposed in either the adult or the youth treatment literature. Numerous relationship variables have been studied, mostly in the adult treatment literature, relative to their contribution to treatment outcome. Rarely has more than one treatment relationship variable been included in the same study and even then, there has not been a theoretical model guiding exploration of the relationship. The result is that there is a large common process factors literature in the adult mental health treatment field, and a growing youth and family treatment literature, but no theoretical framework to guide an understanding of what this literature is telling us about how and why treatment works.

In this paper, we proposed a theoretical model linking various therapeutic relationship constructs to mental health treatment outcome. Our intention in presenting this model was to present a means for organizing the large number of relationship variables and measures that have been studied and to provide a framework to guide future research. This 
model draws upon existing research and some of the theories of therapeutic change that have been proposed in the past.

Clients and therapists bring certain pretreatment characteristics to treatment. These characteristics are believed to influence therapist perceptions and behaviors. Therapist behaviors then influence client's emotional, cognitive, and behavioral reactions to the therapist and to therapy. Research on this first part of the model could lead to the development of intervention strategies to assist therapists in relationship building given the characteristics of their clients. In addition, further research on therapist characteristics and reactions to clients could influence how clinician trainees are chosen and/or could help in identifying which clinicians may need to be taught which relationship building skills. At present, too little is known about client and therapist characteristics and therapist perceptions of clients and how these influence the therapy process in the youth and family mental health treatment literature. It is our hope that this model will guide future research on client and therapist characteristics.

The second part of our model provided a focus on therapist behaviors, such as: therapist selfdisclosure, therapist direct influence behaviors, and therapist interpersonal behaviors. It is hypothesized that these therapist behaviors can influence clients by increasing their sense of autonomy in treatment, their perception of the credibility and persuasiveness of the therapist, and/or fostering various aspects of the therapeutic relationship/therapeutic alliance. At present, very little is known about how therapist behaviors affect various aspects of the therapeutic relationship (Ackerman \& Hilsenroth, 2003; Carroll, 2001; Garfield, 1997; Weinberger, 2002). This is astonishing when one considers how long therapy has been studied. Several theories have contributed to the development of our model relative to the impact of therapist behaviors. Carl Rogers (1957) believed that certain therapist facilitative behaviors, such as empathy, warmth, etc., helped to create an optimal environment in which the client would be able to change. While it is now not generally believed that these behaviors are sufficient for therapy change, we do believe that these are necessary therapist behaviors to induce other therapy relationship variables that lead to better use of evidence-based treatments resulting in optimal treatment outcomes. We also build upon Strong's interpersonal influence model in our hypothesis that therapist behaviors serve to create an impression with clients that the therapist has expertise and high credibility. Once seen as credible, the client will be more likely to feel positively about the therapist and therapy and will be more willing to be influenced or persuaded by the therapist to consider and/or participate in therapeutic activities. It is imperative that studies be designed to further our understanding and test our hypotheses of how therapists' actions and credibility affect the therapeutic relationship. In fact, we may find that informing a client that they are to receive an evidence-based treatment, increases the client's perception of the credibility of the therapist which improves the therapeutic relationship which would then increase the likelihood of successful outcomes with the evidenced-based treatment.

Finally, our review of the literature and proposed model takes a careful look at and dismantles the constructs known as the therapeutic alliance and the therapeutic relationship. Our review of the research suggests that the therapeutic relationship and the therapeutic alliance really appear to be the same construct called by different names and that nothing appears to be gained in separately defining these constructs. Furthermore, the therapeutic alliance/relationship (with the youth or parent or family members) may actually consist of separate constructs that are frequently being assessed simultaneously in general alliance and relationship measures. It is possible that these three separate constructs (emotional connection such as the affective bond with the therapist, cognitive connection such as hopefulness about treatment or willingness to participate in treatment, and behavioral participation in treatment) may occur at different points during treatment. Forcing these constructs together as one construct (therapeutic alliance or therapeutic relationship) in these general measures does not appear to add anything in addition to the three separate constructs and may result in loss of information regarding the therapeutic process. We suggest that efforts be made to increase understanding of each of these separate constructs and their relationships with one another and with treatment outcome. In addition, these constructs need to be carefully considered relative to youth developmental level and to the role of parents and family members in youth treatment. Parents and family members have a significant impact on the lives of youth and their relationships with the therapy process are likely to vary by youth developmental level and potentially impact on whether or not youth have positive outcomes from mental health services. 
In summary, this paper presents a model of how and why therapeutic relationship constructs influence treatment outcomes. Since this type of framework, and the broad expanse of research that helped develop it, has not been available in the child or adult mental health literature, it has been challenging for researchers to pull together all of these studies and constructs coherently, and thus this probably made it difficult for researchers to know where new studies were needed to build upon the literature. We believe that our model will further understanding of the various relationship constructs and lead the way to a new generation of studies. On the basis of this model, we are conducting a meta-analysis of the youth and family treatment literature that will test the general implications of the model (Karver, Handelsman, Fields, \& Bickman, 2004). This is important because these trends can be hard to determine from only looking at a wide collection of individual studies. Hopefully this paper will accomplish its purpose and inspire new and improved research on therapeutic relationship constructs in the youth mental health field particularly when examining the delivery of evidence-based treatments.

\section{ACKNOWLEDGMENTS}

The authors appreciate the assistance of many of the members of the USF Alliance lab such as Christine Totura, Nicole Caporino, Karolina Kaminska, Moira Riley, Jim Cracciolo, and Hong Nguyen.

\section{REFERENCES}

Ackerman, S. J., \& Hilsenroth, M. J. (2003). A review of the therapist characteristics and techniques positively impacting the therapeutic alliance. Clinical Psychology Review, 23(1), 1-33.

Adelman, H. S., Kaser-Boyd, N., \& Taylor, L. (1984). Children's participation in consent to psychotherapy and their subsequent response to treatment. Journal of Clinical and Child Psychology, 13(2), 170-178.

Arkowitz, H. (1995). Common factors or processes of change in psychotherapy? Clinical Psychology: Science and Practice, 2(1), 94-100.

Armbruster, P., \& Kazdin, A. E. (1994). Attrition in child psychotherapy. Advances in Clinical Child Psychology, 16, 81108 .

Armelius, K., \& Holmqvist, R. (2003). Staff members' feelings toward psychiatric patients related to their own and the patient's self-image and gender. Scandinavian Journal of Psychology, 44(2), 69-77.

Atkinson, D. R., \& Schwartz, R. (1984). Effect of discipline on counselor credibility and influence. Counseling and Values, $28,54-62$.

Bandura, A., Caprara, G. V., Barbaranelli, C., Gerbino, M., \& Pastorelli, C. (2003). Role of affective self-regulatory efficacy on diverse spheres of functioning. Child Development, 74(3), 769-782.

Barrett, M. S., \& Berman, J. S. (2001). Is psychotherapy more effective, when therapists, disclose information about themselves? Journal of Counseling and Clinical Psychology, 69(4), 597-603.

Bellak, L., \& Smith, M. B. (1956). An experimental exploration of the psychoanalytic process: Exemplification of a method. Psychoanalytic Quarterly, 25, 385-413.

Bennum, I. (1989). Perceptions of the therapist in family therapy. Journal of Family Therapy, 11, 243-255.

Berg, D. R. (1999). An examination of the relationship between process variables and outcome indicators in the therapeutic use of play with children. Unpublished Dissertation.

Bernier, A., \& Dozier, M. (2002). The client-counselor match and the corrective emotional experience: Evidence from interpersonal and attachment research. Psychotherapy: Theory, Research, Practice, Training, 39(1), 32-43.

Bernstein, B. L., \& Figioli, S. W. (1983). Gender and credibility introduction effects on preceived counselor characteristics. Journal of Counseling Psychology, 30(4), 506-513.

Beutler, L. E., Rocco, F., Moleiro, C. M., \& Talebi, H. (2001). Resistance. Psychotherapy: Theory, Research, Practice, Training, $38(4), 431-436$.

Bickman, L., Andrade, A. R., Lambert, E. W., Doucette, A., Sapyta, J., \& Boyd, A. S. (2004). Youth Therapeutic Alliance in Intensive Treatment Settings. Journal of Behavioral Health Services and Research, 31(2), 134-148.

Bickman, L., Rosof-Williams, J., Salzer, M. S., Summerfelt, W. T., Noser, K., Wilson, S. J., et al. (2000). What information do clinicians value for monitoring adolescent client progress? Professional Psychology: Research and Practice, 31, 70-74.

Bickman, L., Heflinger, C. A., Northrup, D., Sonnichsen, S., \& Schilling, S. (1998). Long term outcomes of family caregiver empowerment. Journal of Child and Family Studies, 7(3), 269-282.

Bohart, A. C. (2000). Paradigm clash: Empirically supported treatments versus empirically supported psychotherapy practice. Psychotherapy Research, 10, 488-493.

Bohart, A. C., Elliot, R., Greenberg, L., \& Watson, J. (2002). Empathy. In J. C. Norcross (Ed.), Psychotherapy relationships that work: Therapist contributions and responsiveness of patients (pp. 89-108). New York: Oxford University Press.

Bordin, E. S. (1979). The generalizability of the psychoanalytic concept of the working alliance. Psychotherapy: Theory, Research and Practice, 16(3), 252-260.

Braswell, L., Kendall, P. C., Braith, J., Carey, M. P., \& Vye, C. S. (1985). "Involvement" in cognitive-behavioral therapy with children: Process and its relationship to outcome. Cognitive Therapy and Research, 9, 611-630.

Burns, B. J., Hoagwood, K., \& Mrazek, P. J. (1999). Effective treatment for mental disorders in children and adolescents. Clinical Child and Family Psychology Review, 2, 199254.

Carroll, K. M. (2001). Constrained, confounded and confused: why we really know so little about therapists in treatment outcome research. Addiction, 96, 203-206.

Catherall, D. R. (1984). The Therapeutic Alliance in Individual, Couple, and Family Therapy. Doctoral Dissertation. Evanston, Illinois.

Chamberlain, P., Patterson, G., Reid, J., Kavanagh, K., \& Forgatch, M. (1984). Observation of client resistance observation of client resistance. Behavior Therapy, 15, 144-155.

Chambless, D. L. (1996). In defense of dissemination of empirically supported psychological interventions. American Psychological Association, 3, 230-235.

Chambless, D. L., \& Hollon, S. D. (1998). Defining empirically supported therapies. Journal of Consulting and Clinical Psychology, 66, 7-18. 
Chorpita, B. F., Yim, L. M., Donkervoet, J. C., Arensdorf, A., Amundsen, M. J., McGee, C., et al. (2002). Toward large-scale implementation of empirically supported treatments for children: A review and observations by the Hawaii Empirical Basis to Services Task Force. Clinical Psychology: Science and Practice, 9, 165-190.

Clarke, G., Hops, H., Lewinsohn, P. M., Andrews, J., Seeley, J. R., \& Williams, J. (1992). Cognitive-behavioral group treatment of adolescent depression: Prediction of outcome. Behavior Therapy, 23, 341-354.

Clarkin, J. F., \& Levy, K. N. (2004). Research on client variables in psychotherapy. In M. Lambert (Ed.), Handbook of psychotherapy and behavior change (5th ed.). New York: Wiley.

Coatsworth, J. D., Santisteban, D. A., McBride, C. K., \& Szapocznik, J. (2001). Brief strategic family therapy versus community control: Engagement, retention, and an exploration of the moderating role of adolescent symptom severity. Family Process, 40, 313-332.

Colson, D. B., Cornsweet, C., Murphy, T., O’Malley, F., Hyland, P. S., McParland, M., et al. (1991). Perceived treatment difficulty and therapeutic alliance on an adolescent psychiatric hospital unit. American Journal of Orthopsychiatry, 61(2), 221229.

Connor-Smith, J. K., \& Weisz, J. R. (2003). Applying treatment outcome research in clinical practice: Techniques for adapting interventions to the real world. Child and Adolescent Mental Health, 8, 3-10.

Cormier, S., \& Nurius, P. S. (2003). Interviewing and change strategies for helpers: Fundamental skills and cognitivebehavioral interventions (5th ed.). Pacific Grove, CA: Brooks/Cole.

Crick, N. R., \& Dodge, K. A. (1994). A review and reformulation of social information-processing mechanisms in children's social adjustment. Psychological Bulletin, 115, 74-101.

DeVet, K. A., Kim, Y. J., Charlot-Swilley, D., \& Ireys, H. T. (2003). The therapeutic relationship in child therapy: Perspectives of children and mothers. Journal of Clinical Child and Adolescent Psychology, 32, 277-283.

DiGiuseppe, R., Linscott, J., \& Jilton, R. (1996). The therapeutic alliance in adolescent psychotherapy. Applied and Preventive Psychology, 5, 85-100.

Dube, J. E., \& Normandin, L. (1999). The mental activities of trainee therapists of children and adolescents: The impact of personal psychotherapy on the listening process. Psychotherapy: Theory, Research, Practice, Training, 36(3), 216-228.

Erez, A., \& Isen, A. M. (2002). The influence of positive affect on the components of expectancy motivation. Journal of Applied Psychology, 87, 1055-1067.

Farber, B. A., \& Lane, J. S. (2002). Positive regard. In J. C. Norcross (Ed.), Psychotherapy relationships that work: Therapist contributions and responsiveness of patients (pp. 175-194). New York: Oxford University Press.

Fields, S., Handelsman, J., Karver, M. S., \& Bickman, L. (March, 2004). Parental and Child Factors that Affect the Therapeutic Alliance. Paper presented at the 17 th annual meeting of the Florida Mental Health Institute's A System of Care for Children's Mental Health: Expanding the Research Base, Tampa, FL.

Fogle, J. E. (1988). Client-therapist interaction and perceived therapeutic outcome. Doctoral Dissertation. University of North Texas.

Frank, J. D., Frank, J. B., \& Cousins, N. (1993), Persuasion and Healing: A Comparative Study of Psychotherapy. Baltimore: The Johns Hopkins University Press.

Freud, A. (1946). The psychoanalytic treatment of children. New York: International Universities Press.

Gabel, S., \& Bemporad, J. (1994). Variations in countertransference reactions in psychotherapy with children. American Journal of Psychotherapy, 48, 111-119.
Garcia, J. A., \& Weisz, J. R. (2002). When youth mental health care stops: therapeutic relationship problems and other reasons for ending youth outpatient treatment. Journal of Consulting and Clinical Psychology, 70(2), 439-443.

Garfield, S. L. (1997). The therapist as a neglected variable in psychotherapy research. Clinical Psychology: Science and Practice, 4(1), 40-43.

Gelso, C. J., \& Carter, J. A. (1985). The relationship in counseling and psychotherapy: Components, consequences, and theoretical antecedents. Counseling Psychologist, 13(2), 155-243.

Gomes-Schwartz, B. (1978). Effective Ingredients in Psychotherapy: Prediction of Outcome From Process Variables. Journal of Consulting and Clinical Psychology, 46(5), 1023-1035.

Gorin, S. S. (1993). The prediction of child psychotherapy outcome: factors specific to treatment. Psychotherapy, 30(1), $152-158$.

Green, J. M. (1996). Engagement and empathy: A pilot study of the therapeutic alliance in outpatient child psychiatry. Child Psychology and Psychiatry Review, 1(4), 130-138.

Green, R., \& Herget, M. (1991). Outcomes of Systemic/Strategic Team Consultation: III. The Importance of Therapist Warmth and Active Structuring. Family Process, 30, 321-336.

Haccoun, D. M., \& Lavigueur, H. (1979). Effects of clinical experience and client emotion on the therapists' responses. Journal of Consulting and Clinical Psychology, 47(1), 227-229.

Hansen, J. C., Zimpfer, D. G., \& Easterling, R. E. (1967). A study of the relationships in multiple counseling. The Journal of Educational Research, 60(10), 461-463.

Hardy, G. E., Stiles, W. B., Barkham, M., \& Startup, M. (1998). Therapist responsiveness to client interpersonal styles during time-limited treatments for depression. Journal of Consulting and Clinical Psychology, 66, 304-312.

Hartley, D. L. (1969). Percieved Counselor Credibility as a Function of the Effects of Counseling Interaction. Journal of Counseling Psychology, 16(1), 63-68.

Hatcher, R., \& Barends, A. (1996). Patients' view of the alliance in psychotherapy: Exploratory factor analysis of three alliance measures. Journal of Consulting and Clinical Psychology, 64, 1326-1336.

Hill, C. E., \& Knox, S. (2002). Self-disclosure. In J. C. Norcross (Ed.), Psychotherapy relationships that work: Therapists' contributions and responsiveness of patients (pp. 255-265). New York: Oxford University Press.

Holmqvist, R. (1998). The influence of patient diagnosis and selfimage on clinicians' feelings. Journal of Nervous and Mental Disease, 186, 455-461.

Horvath, A. O., \& Bedi, R. P. (2002). The alliance. In J. C. Norcross (Ed.), Psychotherapy relationships that work: Therapists' contributions and responsiveness of patients (pp. 37-69). New York: Oxford University Press.

Hoyt, W. T. (1996). Antecedents and effects of perceived therapist credibility: A meta-analysis. Journal of Counseling Psychology, 43, 430-447.

Howe, P. A., \& Silvern, L. E. (1981). Behavioral Observation of Children during Play Therapy: Preliminary Development of a Research Instrument. Journal of Personality Assessment, 45(2), 168-182.

Huey, S. J. (1998). Therapy termination among black, Caucasian, and Latino children referred to community mental health clinics. Doctoral Dissertation. University of California.

Hutchings, J., Appleton, P., Smith, M., Lane, E., \& Nash, S. (2002). Evaluation of two treatments for children with severe behaviour problems: Child behaviour and maternal mental health outcomes. Behavioural and Cognitive Psychology, 30, 279-295.

Jackson-Gilfort, A., Liddle, H. A., Tejada, M. J., \& Dakof, G. A. (2001). Facilitating Engagement of African American Male Adolescents in Family Therapy: A Cultural Theme Process Study. Journal of Black Psychology, 27(3), 321-340. 
Johnson, S. (2000). The therapeutic alliance with early adolescents: Introduction of an instrument. Unpublished doctoral dissertation. Temple University.

Johnson, L. N., \& Wright, D. W. (2002). Revisiting Bordin's Theory on the Therapeutic Alliance: Implications for Family Therapy. Contemporary Family Therapy, 24(2), 257269.

Joyce, A. S., Ogrodniczuk, J. S., Piper, W. E., \& McCallum, M. (2003). The alliance as mediator of expectancy effects in short-term individual therapy. Journal of Consulting and Clinical Psychology, 71, 672-679.

Kalman, T. P. (1983). An overview of patient satisfaction with psychiatric treatment. Hospital and Community Psychiatry, 34(1), 48-54.

Karver, M. S., Lambert, W., \& Bickman, L. (2003, March). Strength based assessment: The Vanderbilt Positive Functioning Index-Revised. Paper presented at the 16th annual meeting of the Florida Mental Health Institute's A System of Care for Children's Mental Health: Expanding the Research Base, Tampa, FL.

Karver, M. S., Handelsman, J., Fields, S., \& Bickman, L. (2004). Meta- analysis of Common Process Factors in Youth and Family Therapy: The evidence for different relationship variables in the child and adolescent treatment outcome literature. Manuscript in preparation.

Kazdin, A. E. (1977). Assessing the clinical or applied importance of behavior change through social validation. Behavior Modification, 1, 427-451.

Kazdin, A. E. (2000). Perceived barriers to treatment participation and treatment acceptability among antisocial children and their families. Journal of Child and Family Studies, 9(2), $157-174$.

Kazdin, A. E., \& Wassell, G. (2000). Predictors of barriers to treatment and therapeutic change in outpatient therapy for antisocial children and their families. Mental Health Services Research, 2, 27-40.

Keijsers, G. P. J., Schaap, C. P. D. R., \& Hoogduin, C. A. L. (2000). The impact of interpersonal patient and therapist behavior on outcome in cognitive-behavior therapy. Behavior Modification, 24, 264-298.

Keithly, L. J., Samples, S. J., \& Strupp, H. H. (1980). Patient motivation as a predictor of process outcome in psychotherapy. Psychotherapy and Psychosomatics, 33, 87-97.

Kendall, P. C., \& Choudhury, M. S. (2003). Children and adolescents in cognitive-behavioral therapy: Some past efforts and current advances, and the challenges in our future. Cognitive Therapy and Research, 27, 89-104.

Kiesler, D. J. (1996). Contemporary interpersonal theory and research: Personality, psychopathology and psychotherapy. New York: Wiley.

Kirsch, I., \& Henry, D. (1977). Extinction versus credibility in the desensitization of speech anxiety. Journal of Consulting and Clinical Psychology, 45(6), 1052-1059.

Kirtner, W. L., \& Carwright, D. S. (1958). Success and failure in client-centered therapy as a function of initial in-therapy behavior. Journal of Consulting Psychology, 22(5), 329-333.

Lambert, M. J. (1992). Psychotherapy outcome research: Implications for integrative and eclectic therapists. In J. C. Norcross \& M. R. Goldfried (Eds.), Handbook of psychotherapy integration (pp. 94-129). New York: Basic Books.

Lambert, M. J., \& Barley, D. E. (2002). Research summary on the therapeutic relationship and psychotherapy outcome. In J. C. Norcross (Ed.), Psychotherapy relationships that work: Therapist contributions and responsiveness to patients (pp. 17-32). Oxford, England: Oxford University Press.

Larson, L. M., Suzuki, L. A., Gillespie, K. N., Potenza, M. T., Bechtel, M. A., \& Toulouse, A. L. (1992). Development and validation of the counseling self-estimate inventory. Journal of Counseling Psychology, 39(1), 105-120.
Lee, D. Y., Hallberg, E. T., Jones, L., \& Haase, R. F. (1980). Effects of counselor gender on perceived credibility. Journal of Counseling Psychology, 27, 71-75.

Littrell, J. M., Caffrey, P., \& Hopper, G. C. (1987). Counselor's reputation: An important precounseling variable for adolescents. Journal of Counseling Psychology, 34, 228-231.

Llewelyn, S., \& Hardy, G. (2001). Process research in understanding and applying psychological therapies. British Journal of Clinical Psychology, 40(1), 1-21.

Lonigan, C. J., Elbert, J. C., \& Johnson, S. B. (1998). Empirically supported psychosocial interventions for children: an overview. Journal of Clinical Child Psychiatry 27, 138145.

Luk, E. S., Staiger, P., Mathai, J., Field, D., \& Adler, R. (1998). Comparison of treatments of persistent conduct problems in primary school children: A preliminary evaluation of a modified cognitive-behavioural approach. Australian and New Zealand Journal of Psychiatry, 32, 379-386.

McKay, M. M., Stoewe, J., McCadam, K., \& Gonzales, J. (1998) Increasing access to child mental health services for urban children and their caregivers. Health and Social Work, 23, 915.

Merriam-Webster's collegiate dictionary (11th ed.). (2003). Springfield, MA: Merriam-Webster.

Meyer, B., Pilkonis, P. A., Krupnick, J. L., Egan, M. K., Simmens, S. J., \& Sotsky, S. M. (2002). Treatment expectancies, patient alliance and outcome: Further analyses from the National Institute of Mental Health Treatment of Depression Collaborative Research Program. Journal of Consulting and Clinical Psychology, 70, 1051-1055.

Milner, J. S. (2003). Social information processing in high-risk and physically abusive parents. Child Abuse and Neglect, 27, 7-20.

Myrick, R. D. (1969). Effect of a Model on Verbal Behavior in Counseling. Journal of Counseling Psychology, 16(3), 185190.

Nelson, R. A., \& Borkovec, T. D. (1989). Relationship of client participation to psychotherapy. Journal of Behavior Therapy and Experimental Psychiatry, 20, 155-162.

Norcross, J. C. (2002). Empirically supported therapy relationship. In J. C. Norcross (Ed.), Psychotherapy relationships that work: Therapist contributions and responsiveness of patients (pp. 316). New York: Oxford University Press.

Nye, C. L., Zucker, R. A., \& Fitzgerald, H. E. (1999). Early familybased intervention in the path to alcohol problems: Rationale and relationship between treatment process characteristics and child and parenting outcomes. Journal of Studies on Alcohol, 13(Suppl.), 10-21.

Padesky, C. A., \& Beck, A. T. (2003). Science and philosophy: Comparison of cognitive therapy and rational emotive behavior therapy. Journal of Cognitive Psychotherapy, 17(3), 211224.

Pinsof, W. M. (1995). Integrative problem-centered therapy: A synthesis of family, individual and biological therapies (Vol. XV). New York: Basic Books, p. 284.

Rogers, C. R. (1951). Client centered therapy. Boston: Houghton Mifflin.

Rogers, C. R. (1957). The necessary and sufficient conditions of therapeutic personality changes. Journal of Consulting Psychology, 21, 95-103.

Rosenberger, E. W., \& Hayes, J. A. (2002). Therapist as subject: A review of the empirical Countertransference literature. Journal of Counseling and Development, 80, 264-270.

Rossberg, J. \& Friis, S. (2003). Staff members' emotional reactions to aggressive and suicidal behavior of inpatients. Psychiatric Services, 54(10), 1388-1394.

Salzer, M. S., Nixon, C. T., Schut, J. A., Karver, M. S., \& Bickman, L. (1997). Validating quality indicators: Quality as relationship between structure, process, and outcome. Evaluation Review, 21(3), 292-309. 
Sanderson, W. C. (2003). Why empirically supported psychological treatments are important. Behavior Modification. Special Issue: Empirically Supported Treatments, 27(3), 290-299.

Sapyta, J. J., Karver, M. S., \& Bickman, L. (1999). Therapeutic alliance: Significance in non-psychotherapy settings. In C. L. Liberton, C. Newman, K. Kutash, \& R.M. Friedman (Eds.), 12th Annual Research Conference Proceedings, A System of Care for Children's Mental Health: Expanding the Research Base (pp. 183-186). Tampa: University of South Florida Press.

Sarlin, N. S. (1992). Working relationships in the treatment of adolescent inpatients: Early treatment predictors and associations with outcome. Doctoral Dissertation, Denver, CO, 233.

Scheel, M. J., Seaman, S., Roach, K., Mullin, T., \& BlackwellMahoney, K. (1999). Client implementation of therapist recommendations predicted by client perception of fit, difficulty of implementation, and therapist influence. Journal of Counseling Psychology, 46(3), 308-316.

Sexton, T. L., Ridley, C. R., \& Kleiner, A. J. (2004). Beyond common factors: Multilevel-process models of therapeutic change in marriage and family therapy. Journal of Marital and Family Therapy, 30(2), 131-149.

Shachner, S. E. (1995). Factors influencing countertransferential responses to latency-aged child psychotherapy patients. Unpublished doctoral dissertation, Columbia University.

Shirk, S. R. (1999). Developmental therapy. In W. K. Silverman \& T. H. Pillendick (Eds.), Developmental issues in the clinical treatment of children (pp. 60-73). Needham Heights, MA: Allyn \& Bacon.

Shirk, S. R., \& Karver, M. (2003). Prediction of treatment outcome from relationship variables in child and adolescent therapy: A meta-analytic review. Journal of Consulting \& Clinical Psychology, 71, 452-464.

Shirk, S. R., \& Karver, M. (in press). Assessing the alliance in adolescent treatment: A clinical construct in search of a measure. In D. Castro-Blanco (Ed.), Treatment engagement with adolescents. Washington, DC: American Psychological Association Press.

Shirk, S. R., \& Saiz, C. (1992). The therapeutic alliance in child therapy: Clinical, empirical, and developmental perspectives. Development and Psychopathology, 4, 713-728.

Simoneau, H., \& Bergeron, J. (2003). Factors affecting motivation during the first six weeks of treatment. Addictive Behaviors, 28(7), 1219-1241.

Smith, E. C., \& Grawe, K. (2003). What makes psychotherapy sessions productive? A new approach to bridging the gap between process research and practice. Clinical Psychology and Psychotherapy, 10(5), 275-285.

Stein, D., Brent, D. A., Bridge, J., Kolko, D., Birmaher, B., \& Baugher, M. (2001). Predictors of parent-rated credibility in a clinical psychotherapy trail for adolescent depression. The Journal of Psychotherapy Practice and Research, 10(1), 1-7.

Stoolmiller, M., Duncan, T., Bank, L., \& Patterson, G. (1993). Some problems and solutions in the study of change: significant patterns in client resistance. Journal of Consulting and Clinical Psychology, 61(6), 920-928.

Strong, S. R. (1968). Counseling: An interpersonal influence process counseling: An interpersonal influence process. Journal of Counseling Psychology, 15(3), 215-224.
Strupp, H. H., Chassan, J. B., \& Ewing, J. A. (1966). Toward the longitudinal study of the psychotherapeutic process. Methods of Research in Psychotherapy.

Taylor, L., Adelman, H., \& Kaser-Boyd, N. (1986). The Origin Climate Questionnaire as a tool for studying psychotherapeutic process. Journal of Child and Adolescent Psychotherapy, 3, $10-16$.

Thompson, B. J., \& Hill, C. E. (1991). Therapist perceptions of client reactions. Journal of Counseling and Development, 69 , 261-265.

Tolan, P. H., Hanish, L. D., McKay, M. M., \& Dickey, M. H. (2002). Evaluating process in child and family interventions: Aggression prevention as an example. American Psychological Association, 16(2), 220-236.

Truax, C. B. (1961). The process of group psychotherapy: Relationship between hypothesized therapeutic conditions and intrapersonal exploration. Psychological Monographs, 75(7, Whole No. 511), 35.

Truax, C. B., Altman, H., Wright, L., \& Mitchell, K. M. (1973). Effects of therapeutic conditions in child therapy. Journal of Community Psychology, 1(3), 313-318.

Truax, C. B., \& Carkhuff, R. R. (1965). The experimental manipulation of therapeutic conditions. Journal of Consulting Psychology, 29, 119-124.

Weerasekera, P., Linder, B., Greenberg, L., \& Watson, J. (2001). The working alliance in client-centered and processexperiential therapy of depression. Psychotherapy Research, $11,221-234$.

Weersing, V. R., \& Weisz, J. R. (2002). Community treatment of depressed youth: Benchmarking usual care against CBT clinical trials. Journal of Consulting and Clinical Psychology, 70(2), 299-310.

Weinberger, J. (2002). Short paper, large impact: Rosenweig's influence on the common factors movement. Journal of Psychotherapy Integration, 12(1), 67-76.

Weisz, J. R., \& Hawley, K. M. (2002). Developmental factors in the treatment of adolescents. Journal of Consulting and Clinical Psychology, 70(1), 21-43.

Weisz, J. R., \& Jensen, P. S. (1999). Efficacy and effectiveness of child and adolescent psychotherapy and pharmacotherapy. Mental Health Services, 1, 125-157.

Wester, S., Vogel, D., \& Archer, J. (2004). Male restricted emotionality and counseling supervision. Journal of Counseling and Development, $82,91-98$.

Williams, E. N. (2003). The Relationship between Momentary States of Therapist Self-Awareness and Perceptions of the Counseling Process. Journal of Contemporary Psychotherapy, 33(3), 177-186.

Williams, E. N., Judge, A. B., Hill, C. E., \& Hoffman, M. (1997). Experiences of novice therapists in prepracticum: Trainees,' clients', and supervisors perceptions of therapists' personal reactions and management strategies. Journal of Counseling Psychology, 44, 390-399.

Williams, E. N., Polster, D., Grizzard, B., Rockenbatjgh, J., \& Judge, A. B. (2003). What happens when therapists feel bored or anxious: A qualitative study of distracting self-awareness and therapists' management strategies. Journal of Contemporary Psychotherapy, 33, 5-18. 
Reproduced with permission of the copyright owner. Further reproduction prohibited without permission. 